\title{
PENGARUH FILLER CARBON BLACK TERHADAP SIFAT DAN MORFOLOGI KOMPOSIT NATURAL RUBBER/POLYPROPYLENE
}

\author{
Bahruddin*, Ida Zahrina, dan Said Zul Amraini \\ Jurusan Teknik Kimia, Fakultas Teknik, Universitas Riau \\ Kampus Bina Widya Km 12.5 Panam, Pekanbaru \\ Email: bahruddin02@yahoo.com
}

\begin{abstract}
Abstrak
Penelitian ini mempelajari pengaruh komposisi dan teknik penambahan filler carbon black (CB) terhadap sifat tensil dan morfologi campuran natural rubber/polypropylene (NR/PP). Sampel campuran disiapkan dengan menggunakan internal mixer pada rasio massa NR/PP 70/30. Filler ditambahkan ke dalam campuran NR/PP dengan komposisi 10\%, 20\% dan 30\% massa. Penambahan filler dilakukan dengan dua cara, pertama dicampur dengan NR terlebih dahulu sebelum pencampuran NR dan PP, dan kedua dicampur bersama-sama NR dan PP dalam internal mixer. Ke dalam campuran juga ditambahkan plastisizer $2 \%$ massa dan kompatibilizer MA-g-PP sebesar 5\% massa. Proses pencampuran menggunakan metode vulkanisasi dinamik pada suhu $180{ }^{\circ} \mathrm{C}$ dan kecepatan rotor $60 \mathrm{rpm}$. Sebagai curative agent digunakan sulfur dengan komposisi $3 \mathrm{phr}$ (per hundred rubber). Sifat tensil campuran diukur menggunakan standar ISO 527-2 Tipe 5A. Morfologi campuran dianalisa menggunakan scanning electron microscopy. Diperoleh bahwa sifat tensil dan morfologi campuran terbaik diperoleh pada komposisi CB 30\% menggunakan teknik pencampuran yang pertama. Pada kondisi tersebut; kuat tarik dan elongation at break campuran masing-masing adalah 9,8 MPa dan 413\%.
\end{abstract}

Kata kunci: natural rubber, termoplastik elastomer, filler carbon black, sifat tensil, morfologi

\begin{abstract}
The effect of carbon black (CB) filler content and mixing technique on tensile properties and morphology of vulcanized natural rubber/polypropylene (NR/PP) blends were studied. The blends were performed in an internal mixer with NR/PP mass ratio of 70/30. The filler was mixed with the blend by two ways. First, $\mathrm{CB}$ was mixed with NR in roll-mill before blending with PP in internal mixer and the second, CB, NR and PP were mixed together in internal mixer. The plasticizer and maleated polypropylene (MA-g-PP) compatibilizer were added at constant value with mass fraction of $2 \%$ and $5 \%$, respectively. Sulfur was used as curative agent with composition of 3 per hundred rubbers (phr) for the dynamic vulcanization process. The mixing was conducted at $180{ }^{\circ} \mathrm{C}$ with the rotor speed of $60 \mathrm{rpm}$. The morphological study on cryogenically fractured samples was performed using scanning electron microscopy and differential scanning calorimetry. The tensile strength and elongation at break were measured by ISO 527-2 Type 5A standard. The results indicate that the addition of $\mathrm{CB}$ as filler could improve the morphology and the properties of the NR/PP blends significantly, especially at CB mass fraction of $30 \%$ and blending by first technique. At these condition, tensile strength and elongation at break were found to be 9,8 MPa and $413 \%$, respectively.
\end{abstract}

Keywords: natural rubber, thermoplastic elastomer, carbon black filler, tensile properties, morphology 


\section{Pendahuluan}

Campuran termoplastik dan elastomer dapat menghasilkan material yang disebut thermoplastic elastomer (TPE). Material tersebut mempunyai sifat dan fungsi yang mirip dengan karet vulkanisasi pada suhu ambien, namun dapat dilelehkan seperti termoplastik pada suhu tinggi. Karakteristik yang unik tersebut dapat menjembatani perbedaan karakteristik antara elastomer konvensional dan termoplastik, dan sangat berguna sebagai alternatif pemanfaatan elastomer konvensional dalam berbagai aplikasi, seperti industri otomotif (Mangaraj, 2005).

Keunggulan TPE yang dibuat dari proses pencampuran suatu elastomer dan termoplastik adalah sifat yang diinginkan dapat ditentukan dengan memilih komponen elastomer dan plastik pada rasio campuran yang sesuai. Banyak kombinasi termolastik dan elastomer yang sudah komersial, diantaranya adalah campuran polypropylene/ ethylene-propylene-diene monomer (PP/EPDM). Namun, EPDM relatif lebih mahal dibandingkan dengan karet alam (NR), sehingga dipelajari kemungkinan mengganti EPDM dengan NR. Campuran PP dan NR diyakini lebih ekonomis dan mempunyai green strength yang tinggi dibandingkan dengan campuran PP/EPDM (Sabet dan Datta, 2000).

Sejauh ini TPE berbasis NR dan PP belum dapat dikembangkan secara komersial karena spesifikasi material tersebut belum dapat bersaing dengan TPE berbasis karet sintetik. Beberapa peneliti sudah mengembangkan metode-metode untuk dapat meningkatkan sifat mekanik campuran NR/PP, diantaranya adalah halogenisasi (Ellul dan Hazelton, 1994) atau maleasi (Nakason dkk., 2006) rantai tak jenuh NR sebelum dilakukan proses vulkanisasi dinamik; dan penambahan kompatibiliser, seperti silane (Kuriakose dkk., 1985) dan transpolyoctenylene rubber atau TOR (Halimatuddahliana dan Akil, 2005). Penulis juga sudah mengembangkan metode kompatibilisasi dengan menggunakan maleated polypropylene (MA-g-PP) untuk meningkatkan sifat TPE berbasis NR dan PP (Bahruddin dkk., 2007). Namun sejauh ini metode-metode tersebut belum dapat mengasilkan peningkatan sifat mekanik sebagaimana diharapkan.

Metode lain yang dapat
dikembangkan adalah dengan menambah komponen filler dalam campuran polimer tersebut. Carbon black (CB) adalah jenis filler yang sudah umum digunakan untuk meningkatkan sifat mekanik karet tervulkanisasi. Namun demikian, beberapa peneliti masih terus mengevaluasi penggunaan $\mathrm{CB}$ untuk meningkatkan performa karet tervulkanisasi (Nukaga dkk., 2006; Rattanasom dkk., 2007; Omnes dkk., 2008).

Pemanfaatan CB sebagai filler untuk meningkatkan sifat mekanik TPE berbasis PP dan NR belum banyak dilakukan. Merujuk pada TPE berbasis PP dan karet sintetik EPDM yang sifat mekaniknya dapat ditingkatkan dengan penambahan filler CB (Sabet dan Datta, 2000), penelitian ini bertujuan untuk meningkatkan sifat tensil campuran NR/PP dengan penambahan filler CB. Sistem campuran yang dibuat juga menggunakan kompatibiliser MA-g-PP, sebagaimana sudah penulis kembangkan pada penelitian sebelumnya.

\section{Teori Dasar}

Sifat suatu campuran polimer sangat ditentukan oleh kompatibilisasi komponenkomponen dalam campuran tersebut. Tujuan kompatibilisasi paduan polimer adalah untuk mendapatkan fasa terdispersi yang stabil dan merata sehingga morfologi dan sifat campuran yang diinginkan dapat tercapai. Secara umum paduan karet/elastomer dengan termoplastik bersifat tak dapat campur (immiscible blend). Paduan polimer tak dapat campur mempunyai tarikan fisik antar komponen yang lemah pada batas fasa, sehingga dapat menyebabkan pemisahan fasa pada kondisi tertentu dan menyebabkan sifatsifat mekanik paduan menjadi kurang baik (Utracki, 1990). Untuk dapat menghasilkan morfologi fasa heterogen yang baik, pencampuran polimer-polimer tak dapat campur memerlukan suatu metode kompatibilisasi. Meskipun tidak dapat menghasilkan paduan yang kompatibel secara termodinamik, namun penambahan kompatibiliser dapat membantu menghasilkan morfologi paduan dengan partikel fasa karet yang terdispersi merata dan berukuran kecil.

Banyak metode kompatibilisasi yang sudah dikembangkan, diantaranya adalah kompatibilisasi paduan polimer dengan metode penambahan suatu kompatibiliser yang terbukti dapat meningkatkan adhesi antar fasa (Utracki, 1990). Misalkan suatu 
paduan antara polimer A (dengan monomer A) dan polimer B (dengan monomer B) ditambahkan suatu kopolimer blok yang terdiri dari monomer A dan B, maka afinitasafinitas alamiah dari blok-blok tersebut terhadap homopolimernya masing-masing akan bertindak melokalisasi kopolimer pada batas fasanya dan membantu melekatkan fasa-fasa tersebut bersama-sama. Polimer blok yang dipilih sebagai kompatibiliser biasanya adalah yang mempunyai keadaan kimiawi yang mirip dengan komponenkomponen yang ada dalam paduan polimer, karena sudah terbukti dapat meningkatkan sifat-sifat campuran. Kompatibilisasi juga dapat dilakukan dengan metode vulkanisasi. Beberapa peneliti melakukan proses vulkanisasi dinamik untuk meningkatkan kompatibilitas campuran PP dan NR (Coran dan Patel, 1981; dan Tinker dkk., 1989).

Meskipun banyak metode
kompatibilisasi yang dapat diaplikasikan pada suatu paduan polimer tak dapat campur, namun tidak semua metode tersebut sesuai dan mudah untuk diterapkan secara langsung. Bahkan kadang-kadang masih harus dikembangkan metode-metode lainnya untuk mendapatkan suatu morfologi paduan polimer dengan fasa terdistribusi secara merata dan stabil serta berukuran kecil.

\section{Metodologi} Bahan

Bahan utama yang digunakan dalam penelitian ini adalah Polipropilen (Polytam PF1000 dengan Melt Flow Index (MFI) 10 g/10 menit pada $230{ }^{\circ} \mathrm{C}$ dan densitas $0,91 \mathrm{~g} / \mathrm{cm}^{3}$ ), karet alam (SIR-20 dengan Mooney Viscosity 70 pada $100{ }^{\circ} \mathrm{C}$ ), carbon black (N330). Bahan aditif yang digunakan meliputi Sulfur 3 per hundred rubber (phr), Mercaptodibenzothiazoledisulfide (MBTS) 0,6 phr, Zinc Oxide 5 phr, Asam Stearat 2 phr, Trimethylquinone (TMQ) jenis Flectol TMQ 1 phr, plastisiser 2\% massa, dan Maleated Polypropylene (MA-gPP) jenis Epolene E-43 Polymer pada konsentrasi 5\% massa.

\section{Peralatan}

Peralatan yang digunakan untuk penyiapan campuran meliputi peralatan untuk pembuatan kompon karet, yaitu Tworoll Mixing Mill, dengan spesifikasi control speed Toshiba UF-S9 400 volt, 3,7 kw; motor Teco $1440 \mathrm{rpm}, 5 \mathrm{hp}$; diameter roll $10 \mathrm{~cm}$ dan panjang roll $35 \mathrm{~cm}$; dan peralatan untuk proses vulkanisasi dinamik, yaitu internal mixer jenis jenis Labo Plastomill, volume chamber $60 \mathrm{cc}$ dengan persentase pengisian $70 \%$. Peralatan untuk pengujian sifat stressstrain adalah Instron Universal Tensile Machine (UTM), merk Orientec Co. Ltd, Model UCT-5T dengan loading maksimum $500 \mathrm{~kg}$. Peralatan untuk pengamatan morfologi menggunakan Scanning Electron Microscope (SEM), model JEOL JSM-T330A.

\section{Penyiapan campuran}

Pencampuran CB dengan campuran NR/PP dilakukan dengan dua teknik berbeda. Pada teknik yang pertama CB dicampur terlebih dahulu dengan kompon NR dalam Roll-Mill. Selanjutnya campuran tersebut dicampur dengan PP di dalam Internal Mixer. Teknik yang kedua adalah CB, kompon NR dan PP dicampur bersama-sama dalam Internal Mixer. Konsentrasi CB dibuat bervariasi, yaitu 10\%, 20\% dan 30\% massa, sedangkan rasio massa NR/PP dibuat tetap sebesar 70/30. Kompon karet merupakan campuran yang terdiri dari karet alam, asam stearat, zinc oxide, MBTS dan sulfur yang dibuat dengan menggunakan Two Roll Mixing Mill. Proses pembuatannya dilakukan pada suhu kamar dengan urutan proses pencampuran ditunjukkan pada Tabel 1. Plastisiser dan kompatibiliser ditambahkan pada pencampuran dalam internal mixer. Tahapan proses dalam internal mixer dengan teknik pencampuran kedua ditunjukkan pada Tabel 2. Proses pencampuran dilakukan pada suhu $180{ }^{\circ} \mathrm{C}$ dan kecepatan rotor $60 \mathrm{rpm}$. Selanjutnya sampel hasil kedua teknik pencampuran tersebut dipersiapkan untuk pengujian sifat mekanik (kuat tarik dan elongation at break) dan pengujian morfologi dengan SEM.

\begin{tabular}{|c|c|c|}
\hline Aktivitas & $\begin{array}{c}\text { Jumlah } \\
\text { (phr) }\end{array}$ & Menit ke \\
\hline Mastikasi karet & 100 & 0 \\
\hline Penambahan ZnO & 5 & 10 \\
\hline $\begin{array}{l}\text { Penambahan asam } \\
\text { stearat }\end{array}$ & 2 & 11 \\
\hline Penambahan TMQ & 1 & 12 \\
\hline Penambahan MBTS & 0,6 & 13 \\
\hline Penambahan Sulfur & 3 & 15 \\
\hline $\begin{array}{l}\text { Penghentian proses } \\
\text { pencampuran }\end{array}$ & - & 20 \\
\hline
\end{tabular}


Tabel 2. Schedule Pencampuran Material dalam Internal Mixer

\begin{tabular}{lc}
\hline Aktivitas & Menit ke \\
\hline Pelelehan PP & 0 \\
Penambahan plastisiser & 3 \\
Penambahan kompon & 4 \\
Penambahan kompatibiliser & 7 \\
Penghentian proses & \\
pencampuran & 12 \\
\hline
\end{tabular}

\section{Pengujian sifat mekanik}

Sifat mekanik yang diuji adalah kuat tarik dan elongation at break. Penyiapan sampel untuk pengujian sifat mekanik dilakukan dalam dua tahap, yaitu pembuatan lembaran $(s l a b)$ dan pemotongan lembaran tersebut menjadi spesimen uji. Pembuatan lembaran menggunakan peralatan Hydraulic Hot Press, model Gonno Hydraulic Press, load $210 \mathrm{~kg} / \mathrm{cm}^{2}$. Peralatan tersebut dilengkapi dengan pemanas elektrik dan pendingin air. Ukuran lembaran adalah $15 \times 21 \mathrm{~cm}$ dengan ketebalan 1,4 mm. Kondisi operasi pada saat pembuatan lembaran adalah tekanan 200 bar dan suhu $180{ }^{\circ} \mathrm{C}$. Pemotongan lembaran menjadi spesimen uji menggunakan peralatan specimen punching machine. Selanjutnya seluruh spesimen disimpan dalam suatu kantong kedap udara pada suhu $25^{\circ} \mathrm{C}$ sampai waktu pengujian dilakukan. Pengujian kuat tarik dan elongation at break berdasarkan ISO 527-3-5 load 100 kgf dan laju 50 mm/menit.

\section{Pengujian SEM}

Pengujian dilakukan pada permukaan patahan sampel. Untuk menghindari perubahan bentuk permukaan fasa ketika dipatahkan, sampel terlebih dahulu direndam dalam nitrogen cair. Sampel selanjutnya dilapisi dengan emas selama 4 menit dengan kuat arus ion $10 \mathrm{~mA}$ (ketebalan $\pm 300 \mathrm{~A}^{\circ}$ ), menggunakan JEOL Fine Coat (Ion Sputter). Pelapisan tersebut dilakukan untuk menghindari timbulnya muatan elektrostatik dari sampel pada saat pengujian SEM. Hasil pengujian SEM berupa mikrograf yang digunakan untuk mengamati morfologi campuran (fasa dan distribusi fasa).

\section{Hasil dan Pembahasan}

Pengaruh kadar komposisi filler $\mathrm{CB}$ dalam campuran NR/PP dan teknik pencampurannya dapat dilihat pada Gambar 1 dan 2. Dibandingkan dengan sistem campuran $\mathrm{NR} / \mathrm{PP}$ tanpa penambahan filler, peningkatan sifat kuat tarik baru terjadi pada komposisi $\mathrm{CB}$
30\% massa, yaitu sebesar 27\% (dari 7,7 MPa menjadi 9,8 MPa). Sifat tensil tersebut mengalami penurunan terendah pada komposisi CB $20 \%$ massa. Hal ini menunjukkan bahwa kompatibilisasi yang relatif baik antara CB, NR dan PP baru dapat terjadi pada komposisi $\mathrm{CB}$ yang relatif tinggi untuk rasio NR/PP 70/30. Namun hal ini juga sangat dipengaruhi oleh teknik pencampuran. Distribusi fasa CB yang dicampur terlebih dahulu dengan NR pada roll-mill terlihat lebih homogen dalam fasa NR/PP, sebagaimana ditunjukkan pada Gambar 3 dan Gambar 4. Sehingga teknik pencampuran pertama menghasilkan sifat tensile stength campuran NR/PP yang lebih baik $60 \%$ dibandingkan dengan teknik yang kedua pada komposisi CB $30 \%$ massa.

Pada campuran NR/PP ini, komponen NR dan filler CB merupakan fasa terdistribusi dan komponen PP merupakan fasa matrik. Ukuran partikel yang semakin kecil dan dispersi yang semakin merata dari fasa terdistribusi dapat menghasilkan sifat tensil campuran yang semakin meningkat (Coran dan Patel, 1981). Pada penelitian ini diperoleh bahwa teknik pencampuran yang pertama, yaitu pencampuran CB dengan NR dilakukan terlebih dahulu dalam Roll-Mill sebelum dicampur dengan PP di Internal Mixer, dapat menghasilkan distribusi partikel CB dalam matrik yang lebih baik. Hal ini dibuktikan dengan sifat tensil campuran yang lebih baik (Gambar 1 dan 2) dan hasil pengamatan SEM (Gambar 3 dan 4).

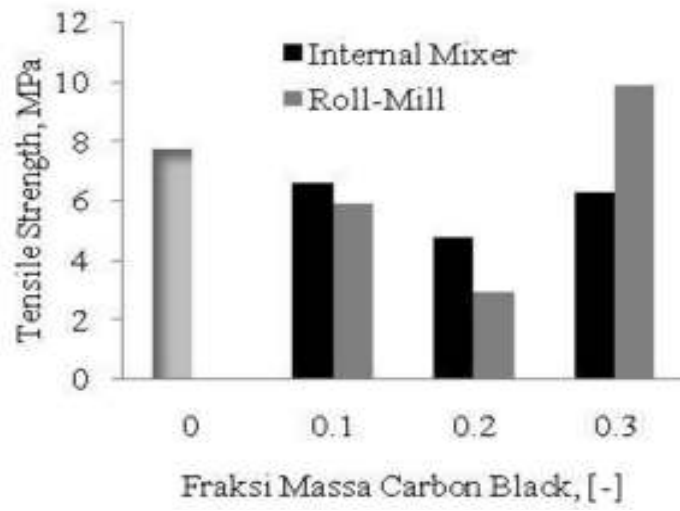

Gambar 1. Pengaruh komposisi CB terhadap sifat kuat tarik untuk teknik pencampuran berbeda

Adanya filler dalam campuran NR/PP menyebabkan sifat elongation at break menurun. Hal ini terjadi pada kedua teknik pencampuran tersebut. Namun untuk sistem 


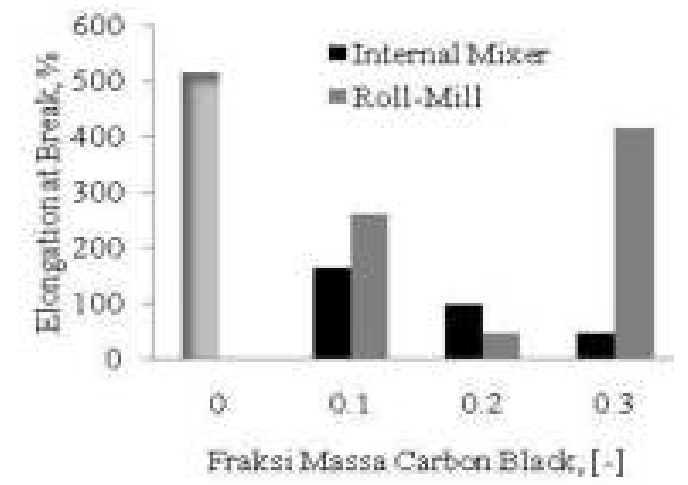

Gambar 2. Pengaruh komposisi CB terhadap sifat elongation at break untuk teknik pencampuran berbeda

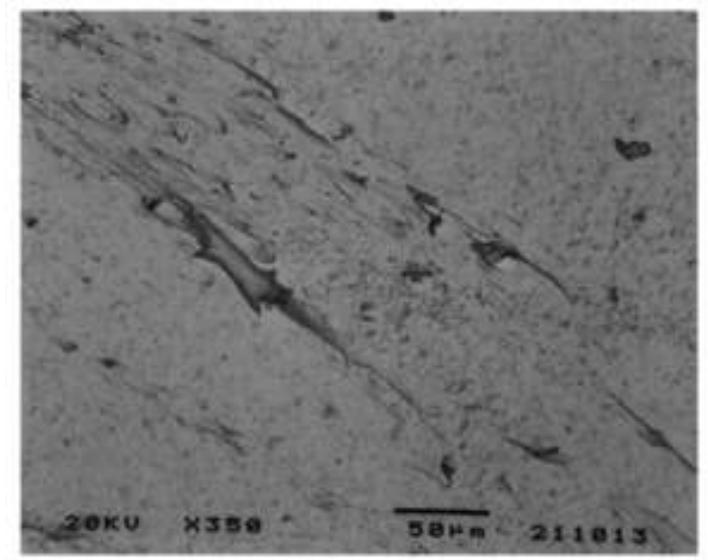

Gambar 3. Mikrograf SEM campuran NR/PP untuk teknik pencampuran CB dalam roll-mill pada komposisi CB $30 \%$ massa

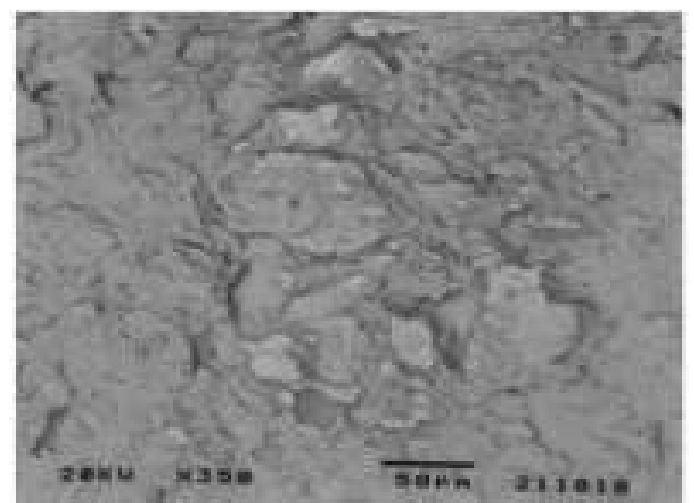

Gambar 4. Mikrograf SEM campuran NR/PP untuk teknik pencampuran CB dalam internal mixer pada komposisi $\mathrm{CB}$ $30 \%$ massa

campuran yang dibuat dengan teknik kedua (CB dicampur terlebih dahulu dengan NR dalam Roll-Mill), penurunan elongation at break relatif kecil, yaitu dari 512\% (tanpa filler) menjadi 413\% (komposisi CB 30\%). Secara umum, penurunan sifat tersebut merupakan konsekwensi dari kontribusi sifat CB yang relatif tidak mempunyai sifat elastis.

Vulkanisasi dinamik fasa NR selama proses pencampuran meningkatkan viskositas campuran (Kuriakose dkk., 1985). Akibatnya aksi gesekan yang terjadi semakin meningkat selama proses pencampuran, sehingga ukuran partikel menjadi lebih kecil dan dispersi fasa NR dalam matrik PP lebih merata. Oleh karena itu, vulkanisasi dinamik dapat meningkatkan sifat kuat tarik dan elongation at break. Vulkanisasi dinamik fasa NR dalam matrik PP mengubah sifat stress-strain menjadi seperti karet vulkanisasi, dimana ukuran partikel NR kecil dan dispersinya dalam PP merata. Ukuran dispersi yang kecil dan sifat crosslinked mejadikan partikel-partikel terdistribusi lebih memudahkan inisiasi dan pergerakan aliran matrik. Pada campuran vulkanisasi dinamik dengan kadar NR lebih tinggi, perubahan bentuk fasa NR relatif kecil. Jika terjadi keretakan atau patah (fracture), hal ini disebabkan oleh aksi gesekan antara fasa NR dan PP.

Tabel 3. Perbandingan Sifat Mekanik Berbagai Sistem Campuran NR/PP pada Rasio Massa 70/30

\begin{tabular}{|c|c|c|}
\hline \multirow[b]{2}{*}{ Sistem Campuran } & \multicolumn{2}{|c|}{ Sifat Mekanik } \\
\hline & $\begin{array}{c}\text { Kuat tarik } \\
\text { (Мра) }\end{array}$ & $\begin{array}{c}\text { Elongation at } \\
\text { Break }(\%)\end{array}$ \\
\hline $\begin{array}{l}\text { NR/PP dengan } \\
\text { kompatibiliser Trans- } \\
\text { Polyoctenylene Rubber } \\
\text { atau TOR } \\
\text { (Halimatuddahliana } \\
\text { Dan Akil, 2005) }\end{array}$ & 4,3 & 250 \\
\hline $\begin{array}{l}\text { NR/PP dengan } \\
\text { kompatibiliser Silane } \\
\text { dan penambahan filler } \\
\text { Silika } 20 \text { phr } \\
\text { (Kuriakose dkk., 1985) }\end{array}$ & 8,9 & 200 \\
\hline $\begin{array}{l}\text { NR/PP dengan } \\
\text { kompatibiliser } \\
\text { Maleated Natural } \\
\text { Rubber atau MNR } \\
\text { (Nakason dkk., 2006) }\end{array}$ & 6 & 260 \\
\hline $\begin{array}{l}\text { NR/PP dengan } \\
\text { kompatibiliser } \\
\text { Maleated } \\
\text { Polypropylene atau } \\
\text { MA-g-PP (Bahruddin } \\
\text { dkk., 2007) }\end{array}$ & 7,7 & 512 \\
\hline $\begin{array}{l}\text { NR/PP dengan } \\
\text { kompatibiliser MA-g-PP } \\
\text { dan penambahan filler } \\
\text { carbon black } \\
\text { (penelitian ini) }\end{array}$ & 9,8 & 413 \\
\hline
\end{tabular}

Catatan : 
a Pada rasio massa MNR/PP 80/20

Penambahan kompatibiliser MA-g-PP menyebabkan terjadinya peningkatan interaksi kimia matrik. Interaksi tersebut menurunkan tegangan muka dan menghasilkan adhesi yang lebih baik, sehingga dapat membantu meningkatkan dispersi dan mempertahankan reflokulasi partikel NR yang terdispersi. Oleh karena itu, penggunaan kompatibiliser tersebut dapat menghasilkan peningkatan sifat kuat tarik dan elongation at break dari campuran (Bahruddin dkk., 2007). Perbandingan sifat kuat tarik dan elongation at break untuk berbagai sistem campuran NR/PP pada rasio massa 70/30 ditunjukkan pada Tabel 3. Kami mendapatkan bahwa penggunaan filler CB dan kompatibiliser MA-g-PP dapat menghasilkan sifat mekanik yang relatif lebih baik dibandingkan dengan sistem campuran yang dibuat dengan metode lainnya, terutama sifat kuat tarik.

\section{Kesimpulan}

Penambahan filler CB dalam campuran NR/PP dapat meningkatkan sifat tensil campuran tersebut. Morfologi terbaik diperoleh dengan metode dimana CB dan NR dicampur terlebih dahulu dalam Roll Mill sebelum dicampur PP dalam Internal Mixer. Dengan metode tersebut, pada rasio massa NR/PP 70/30 dan komposisi CB $30 \%$ massa, diperoleh kuat tarik sebesar 9,8 $\mathrm{MPa}$ dan elongation at break $413 \%$.

\section{Ucapan Terima Kasih}

Penulis menyampaikan ucapan terima kasih kepada Direktur Penelitian dan Pengabdian kepada Masyarakat (DP2M) yang telah membiayai penelitian ini melalui DIPA Universitas Riau Tahun 2009. Ucapan terima kasih juga disampaikan kepada Putra Firdaus dan Liana Solehah, mahasiswa Program Sarjana Jurusan Teknik Kimia Universitas Riau, yang telah membantu pelaksanaan penelitian ini.

\section{Daftar Pustaka}

Bahruddin; Sumarno; Wibawa, G.; Soewarno, N., The Effect of Maleated Polypropylene on the Morphology and Mechanical Properties of Dynamically Vulcanized Natural Rubber/Polypropylene Blends, in Proceeding of $14^{\text {th }}$ Regional Symphosium of Chemical Engineering (RSCE), 6-7 December 2007, Yogyakarta, Indonesia, 2007.
Coran, A. Y.; Patel, R., Elastoplastic Compositions of Cured Diene Rubber and Polypropylene, U. S. Patent No. 4,271,049, June 1981.

Ellul, M. D.; Hazelton, D. R., Chemical Surface Treatments of Natural Rubber and EPDM Thermoplastic Elastomers: Effect on Friction and Adhession, Rubber Chemistry and Technology, 1994, Vol. 67(4), 582-601.

Halimatuddahliana, H. I.; Akil, H. Md., The Effect of trans-Polyoctenylene Rubber and Dynamic Vulcanization on Properties of $P P / E P D M / N R$ Blends, Progress in Rubber, Plastics and Recycling Technology, 2005, Vol. 21(1), 39-53.

Kuriakose, B.; Chakraborty, S. K.; De, S. K., Scanning Electron Microscopy Studies On Tensile Failure of Thermoplastic Elastomers From Polypropylene-Natural Rubber Blends, Materials Chemistry And Physics, 1985, Vol. 12(2), 157-170.

Mangaraj, D., Rubber Recycling by Blending with Plastics, in De, S. K.; Isayev, A. I.; and Khait, K. (Ed.), Rubber Recycling, Taylor \& Francis, New York, 2005, 18-25.

Nakason, C.; Saiwari, S.; Kaesaman, A., Thermoplastic Vulcanizates Basedon Maleated Natural Rubber/PolypropyleneBlends: Effect of Blend Ratios on Rheological, Mechanical, and Morphological Properties, Polymer Engineering and Science, 2006, Vol. 46(5), 594-600.

Nukaga, H.; Fujinami, S.; Watanabe, H.; Nakajima, K.; Nishi, T., Evaluation of the Mechanical Properties of Carbon Black Reinforced Natural Rubber by Atomic Force Microscopy, International Polymer Science and Technology, 2006, Vol. 34(4), 509-515.

Omnes, B.; Thuillier, S.; Pilvin, P.; Grohens, Y.; Gillet, S., EffectiveProperties of Carbon Black Filled Natural Rubber: Experiments and Modelling, Composite Part A: Applied Science and Manufacturing, 2008, Vol. 39(7), 11411149.

Rattanasom, N.; Saowapark, T.; Deeprasertkul, C., Reinforcement of Natural Rubber with Silica/Carbon Black Hybride Filler, Polymer Testing, 2007, Vol. 26(3), 369-377. 
Sabet, S.A.; Datta, S., Thermoplastic Vulcanizates", in Paul, D. R., Bucknall C. B., (Ed.), Polymer Blends, Vol. 2, John Wiley \&Sons, 517-555, 2000.
Tinker, A. J.; Icenogle, R. D.; Whittle, I., Natural Rubber Based TPEs, Rubber World, 1989, Vol. 199, 25-29.

Utracki, L. A., Polymer Alloys and Blends: Thermodynamics and Rheology, Hanser Publishers, 1990. 